\title{
Dragonfly (Odonata) community structure in the Eastern Highlands Biodiversity Hotspot of Zimbabwe: potential threats of land use changes on freshwater invertebrates
}

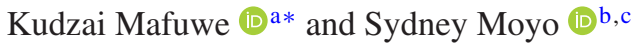 \\ ${ }^{a}$ Department of Entomology, Natural History Museum of Zimbabwe, Bulawayo, Zimbabwe; ${ }^{b}$ Department \\ of Earth Sciences, Albany Museum, Grahamstown, South Africa; ${ }^{c}$ Department of Zoology and \\ Entomology, Rhodes University, Grahamstown, South Africa
}

(Received 20 July 2018; final version received 9 April 2020)

\begin{abstract}
We examined the diversity and potential drivers of dragonfly distribution in a biodiversity hotspot of Southern Africa (Eastern Highlands, Zimbabwe) by surveying 30 sites (13 lentic and 17 lotic habitats) located within this region. Additionally, we identified the anthropogenic factors that may threaten Odonata diversity and abundance. Our results revealed that 27 odonate species are associated with dams and ponds, one species is associated with streams and four species are associated with swamp forests. Considering odonate diversity between protected and unprotected areas, we found significantly higher diversity of odonates in streams in protected areas compared to non-protected areas. Broadly, we found anthropogenic activities (e.g. commercial exotic tree plantations, mining activities, vegetation clearing) possibly affect Odonata diversity (by decreasing abundance and diversity) compared to those within protected and undisturbed habitats. Our results reveal that several human activities like human encroachment into riverine habitats potentially threaten the existence of freshwater species in this biodiversity hotspot and biodiversity hotspots elsewhere.
\end{abstract}

Keywords: lotic; lentic; Zygoptera; Anisoptera; abundance; Africa

\section{Introduction}

The Eastern Highlands Biodiversity Hotspot is a hub of endemism in Zimbabwe; known for its high number of endemic species of fauna and flora (Branch, Bayliss, \& Tolley, 2014; Dalu et al., 2016). The highlands are of high economic significance to Zimbabwe due to the number of rivers and tributaries that originate from the mountains (Jonnalagadda \& Mhere, 2001; Terink, Droogers, \& en Aa's, 2014). These rivers in Zimbabwe, congruent to rivers in the rest of the world, play a vital role in human livelihoods (sensu Darwall, Smith, Tweddle, \& Skelton, 2009; Lamsal, Pant, Kumar, \& Atreya, 2015) and are undergoing substantial alteration due to climate and land use changes from an increasing human population (Zuo et al., 2016; Mukheibir, 2017). Mitigating the pressures facing freshwater systems in the world requires scientists and environmental managers to understand the ecological mechanisms, and ultimately the factors affecting biodiversity in ecosystems (Lopes-Lima et al., 2017; Sterling et al., 2017).

*Corresponding author. Email: kudzimaffy@gmail.com 
Odonata species have been identified as one of the priority taxa for environmental health and conservation (sensu Clausnitzer, Simaika, Samways, \& Daniel, 2017; Hemalatha, 2017). Odonates are particularly sensitive to human disturbance and their diversity as larvae and adults tends to decrease whenever there are high levels of human disturbances and pollution, thereby making them suitable quality indicators for both terrestrial and aquatic ecosystems (de Oliveira-Junior et al., 2017; Kemabonta, Adu, \& Ohadiwe, 2017). The top-down effects (predation capacities) of odonates have also enabled them to be used as biological control agents for disease-spreading pests like mosquitoes (Bhusnar \& Sathe, 2017; Faithpraise et al., 2014).

However, Odonata species are not widely used in Zimbabwe as habitat quality indicators or as biocontrol agents because many of the endemic species are yet to be described; with many areas of Zimbabwe still poorly explored (Darwall et al., 2009; Dijkstra \& Clausnitzer, 2014; Dijkstra, Clausnitzer, Mézière, Kipping, \& Schütte, 2011; Samways, 2002; Suhling, Samways, Simaika, \& Kipping, 2009). There are limited records on the abundances and species distributions of most species from Zimbabwe, with most records dating back at least $30^{+}$years (Dijkstra \& Clausnitzer, 2014; Kipping, Dijkstra, Clausnitzer, Suhling, \& Schütte, 2009). The scanty data of odonate species descriptions in Zimbabwe may very well be true for many other African countries (Bouchelouche, Kherbouche-Abrous, Mebarki, Arab, \& Samraoui, 2015; Dumont \& Verschuren, 2005; Dijkstra et al., 2011) as well as across the globe (e.g. Dijkstra \& Clausnitzer, 2014; Khan, 2015). Consequently, Odonata species have increasingly acquired a high conservation status and are commonly included in red-lists of many countries (Dijkstra \& Clausnitzer, 2014; Samways, 2002).

To date, more than 120 species have been recorded, from more than 170 localities in the Eastern Highlands Biodiversity Hotspot of Zimbabwe (Kipping et al., 2009; Pinhey, 1984). Furthermore, two endemic species to this region, Africallagma cuneistigma and Pseudagrion vumbaense, are hardly studied yet they carry a high conservation importance; because knowledge of these two species remains rudimentary (Darwall et al., 2009; Dijkstra \& Clausnitzer, 2014). Africallagma cuneistigma was first recorded in 1958 in the Bundi river (Pinhey, 1961), Chimanimani mountain and was again recorded in 2013 at the same locality (Dijkstra \& Kipping 2013). Pseudagrion vumbaense was first recorded in 1958 in Vumba and again in 1966 in the Chirinda forest in the Eastern Highlands of Zimbabwe. It was more recently recorded in 2013 at four localities around the biodiversity hotspot (Dijkstra \& Kipping, 2013).

Most Odonata species recorded in the Eastern Highlands of Zimbabwe were recorded from lotic habitats (Clausnitzer et al., 2012; Kipping et al., 2009) with very few studies considering species diversity in lacustrine environments. While these aforementioned surveys have contributed to our knowledge of species distributions in Africa, in most cases the data lack pertinent information on species ranges, habitat requirements, and threats to the species (e.g. land use practices); aspects that are crucial to the conservation of biodiversity (Allan \& Castillo, 2007). Furthermore, a few studies have been conducted in Zimbabwe to assess the effect of industrial and sewage effluent on Odonata (sensu Dube, Makaka, \& Sibanda, 2010). Elsewhere, thermal tolerances of Odonata larvae families have also been documented (Lake Kariba, Zimbabwe; Makaure et al., 2015). A few other ecological studies on Odonata species have been conducted in other African countries (e.g. Damm, Dijkstra \& Hadrys, 2010; Hart, Bowker, Tarboton, \& Downs, 2014). Understanding the factors that influence the distribution and species responses to perturbations is necessary as it helps ecologists to prioritize the best management practices for sustaining habitat quality, biodiversity, and ecosystem services within biodiversity hotspots (sensu Allan \& Castillo, 2007).

The high endemism in the Eastern Highlands Biodiversity Hotspot has not been spared by anthropogenic activities associated with the increasing human populations and human encroachment into protected areas. Zimbabwe's biodiversity hotspot is under intense pressure from 
agriculture, illegal logging, and small-scale mining activities, which pose a threat to both terrestrial and freshwater habitats and the diverse species therein (Gandiwa \& Gandiwa, 2012). For instance, when gold was discovered in the alluvial river sands in the upland grasslands of the Chimanimani mountain in the year 2000, over 10,000 small-scale miners from Zimbabwe and Mozambique invaded the protected areas and began digging in and around riverbeds. These mining activities have led to the destruction of the riparian vegetation, while discharge and depth of the rivers have been altered as evidenced by aerial images analysed by researchers (e.g. Ndunguru, Dondeyne, \& Mulaboa, 2006)

Presently, the endemic species found in the Eastern Highlands of Zimbabwe are listed as threatened (Dijkstra \& Clausnitzer, 2014; IUCN, 2019. The endemic Odonata species and other freshwater species face potential threats due to the destruction of their habitat by the anthropogenic induced activities (Clausnitzer et al., 2009; Harisha \& Hosetti, 2017). The IUCN (2019) asserts the need for more data to be collected on general species distribution, which will urgently confirm species distribution range and population status for many species that have been recorded in the eastern highlands, including the two endemic species Africallagma cuneistigma and Pseudagrion vumbaense. To this end, we addressed the following aims: (i) to describe Odonata species found in the Afromontane region of Zimbabwe in terms of total abundance and diversity; (ii) to determine habitat associations of the Odonata species in the Eastern Highlands Biodiversity of Zimbabwe; and (iii) to identify and assess the natural and anthropogenic threats facing these and other Odonata species.

\section{Material and methods}

\section{Study area}

The study was conducted in the Eastern Highlands of Zimbabwe; a biodiversity hotspot along the Chimanimani-Inyanga Biodiversity Corridor (Figure 1). The study sites were located in five protected areas: Nyanga National Park, Chimanimani National park, Vumba Botanical Garden, Chirinda Forest Botanical Reserve, the Stapleford Forest along with adjacent communal areas along the corridor. All sampled habitats were characterized and marked during a preliminary survey in August 2016. Following this survey, habitats were mapped and grouped into lotic (seeps, springs, creeks, streams and rivers) and lentic habitats (dams, pools, marshes, lakes, bogs, etc.) according to the physical characteristics of the waterbody, and the availability of water resources. Thirty sites were selected, comprising 13 lentic and 17 lotic habitats (Table S1 in Supplementary File). Surveys were conducted between October 2016 and June 2017 with each site sampled once in each of the three seasons recognized in Zimbabwe; i.e. in October 2016 (hot and dry season), January (hot and wet season) and June 2017 (cold and dry season); depending on the accessibility of the sites.

\section{Field collections}

Standardized, timed (30-min) surveys were used to survey adult odonates. All sampling was conducted between 1000 hours and 1600 hours, when Odonata activity is high. The surveys were conducted by two observers (two experienced Odonata taxonomists) and one recorder, walking through all the riparian habitats (intensively searching) and recording individuals flying over water and emergent vegetation, or within $2 \mathrm{~m}$ of the water's edge. A $5 \times 500 \mathrm{~m}$ transect was used at each site and the Odonata species encountered were identified and counted. Identification of species was predominantly done for each species using close-focusing binoculars and field 


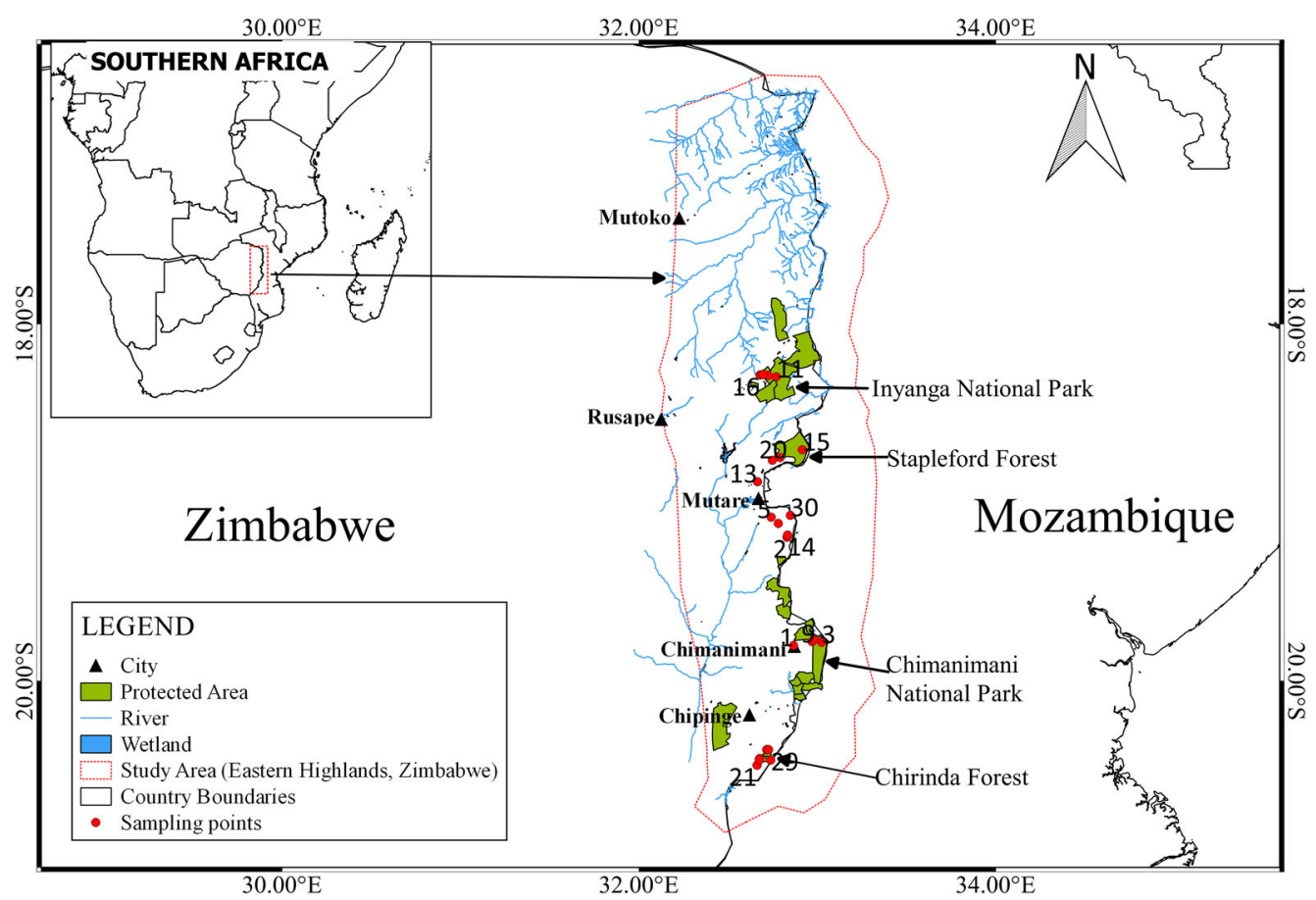

Figure 1. Map of the study area (Eastern Highlands of Zimbabwe) showing sampling points (1-30) as listed in Supplementary Table 1.

guides by the two observers to avoid misidentifications. Where necessary, one individual of each species was caught with sweep nets and examined using a hand-lens to confirm identification and subsequently released. Furthermore, species were photographed to provide a permanent record of identification and occurrence. Where further identification was required, voucher specimens were captured and transported in labelled paper envelopes for further identification using regional keys.

\section{Data analysis}

\section{Diversity and abundance (Objective 1)}

To address objective 1, the Shannon diversity index $(\mathrm{H})$ was used to provide a measure of relative diversity. Diversity indices between habitat types and amongst elevation zones were compared using Mann-Whitney and Kruskal-Wallis tests respectively. To address the potential significance of protected areas for freshwater species, we compared diversity between protected and unprotected areas.

\section{Associations between Odonata species and biotopes (Objective 2)}

Diversity of Odonata is known to change with elevation (Samways, 2008); therefore, we grouped sites into elevation zones according to Timberlake (1994a) based on the elevation of the sites, in metres [high $(>1800 \mathrm{~m})$, high to medium (1400-1800m), medium (1000-1400 m) and low $(<1000 \mathrm{~m})$ ]. Subsequently, we used a Kruskal-Wallis test to compare Odonata diversity across elevation zones. Furthermore, we grouped sites into biotopes [swamp forests, small mountain 
streams with calm pools, fluctuating pools and marshes, permanent pools, lakes, vleis or marshes, sluggish rivers with quiet pools, artificial ponds and dams, swift rivers and streams with invasive alien trees] (Samways, 2008; Table S1). We used a multivariate approach [principal component analysis (PCA)] to determine the association between the Odonata species and sampled biotopes. To further augment the results from the PCA analysis, we also used an indicator value (IndVal) analysis (Dufrêne \& Legendre, 1997) to assess the indicator species for different habitats. IndVal analysis has been advocated as a useful method for assessing habitat associations between species and the habitats they rely on (Podani \& Csányi, 2010). The significance of IndVal indices was assessed using 10,000 Monte Carlo permutations.

\section{Identifying and assessing the anthropogenic threats (Objective 3)}

The anthropogenic factors were identified during the preliminary surveys (habitat characterization). Transects were therefore also set up at sites that fell within: (i) protected areas reforested using exotic trees; (ii) communal areas; (iii) large scale exotic tree plantations; (iv) illegal mining areas; and (v) protected areas where vegetation is regularly cleared and modified for tourism. Subsequently, to assess the effects of anthropogenic factors on Odonata diversity, we compared these sites against the diversities recorded from the protected and undisturbed sites using Mann-Whitney tests.

\section{Results}

\section{General diversity and abundance of Odonata (objective 1)}

From the 30 sites sampled, we recorded 81 species (27 Zygoptera and 54 Anisoptera) and 10 families from 2678 individual adults (Table S2 in Supplementary File). Family Libellulidae was the most dominant species (44 species), with the Coenagrionidae family (18 species) being the second most dominant. The most ubiquitous species was Trithemis arteriosa (374 individuals) followed by Pseudagrion kersteni (319 individuals). Only one individual of Zygonoides fuelleborni was recorded along the Nyamukwarara River.

Within protected areas, lotic habitats had higher odonate diversity $(H=2.13)$ compared to lentic habitats $(H=1.76 ; \mathrm{U}=63 ; \mathrm{Z}=-2.02 ; p<0.05)$. However, in unprotected areas, lentic habitats had higher diversity $(\mathrm{H}=2.10)$ compared to lotic habitats $(\mathrm{H}=1.60 ; \mathrm{U}=123 ; \mathrm{Z}=-$ $2.94 ; p<0.05)$. Further, lotic habitats in protected areas had higher odonate diversity than outside the protected area $(\mathrm{U}=85 ; \mathrm{Z}=-2.81 ; p<0.05)$, whereas lentic habitats within protected areas had lower odonate diversity compared to those found outside the protected area $(\mathrm{U}=75.5 ; \mathrm{Z}=-$ 2.53; $p<0.05$; Figure 2).

Considering odonate diversity at different elevations, significant differences (Kruskal-Wallis $\mathrm{H}=8.3, p<0.05 \mathrm{df}=3, \mathrm{~N}=75)$ in Odonata diversity occurred between medium and low elevations zones (Figure 3).

\section{Habitat associations (objective 2)}

Anisoptera species were ubiquitous (PCA; explains $47.3 \%$ of the total variation) with no discernible biotope associations (Figure 4a). The majority of Zygoptera species were associated with artificial dams and ponds (PCA; explains $66.8 \%$ of the total variation; Figure 4b) including Ischnura senegalensis, Azuragrion nigridorsum, Ceriagrion glabrum, Africallagma fractum, 


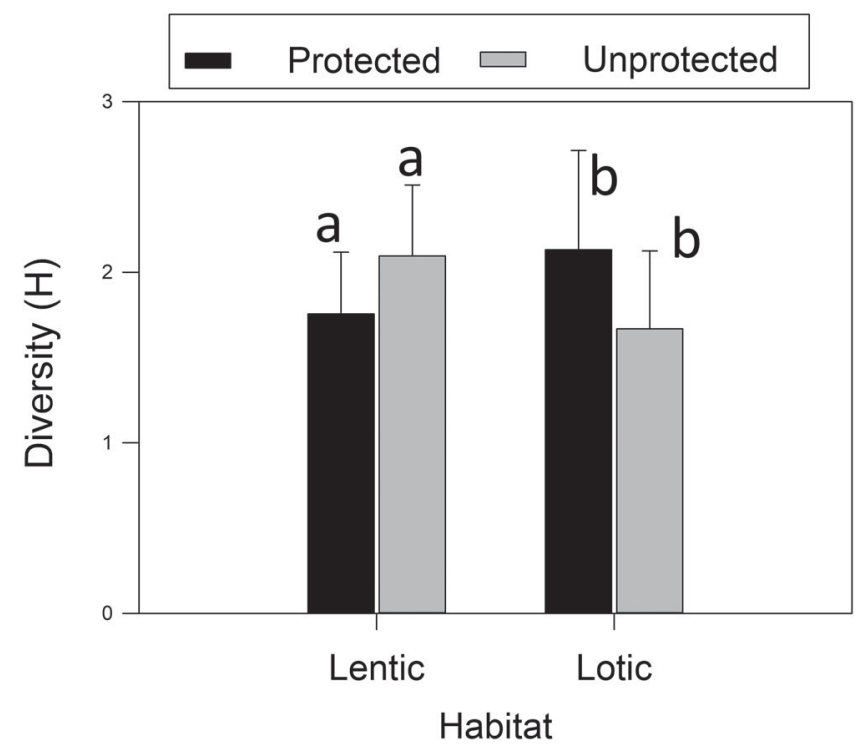

Figure 2. Odonata species diversity within and outside protected areas (per each habitat type). Different letters denote significant differences $(p<0.05)$ among habitat comparisons. Error bars are based on standard deviations.

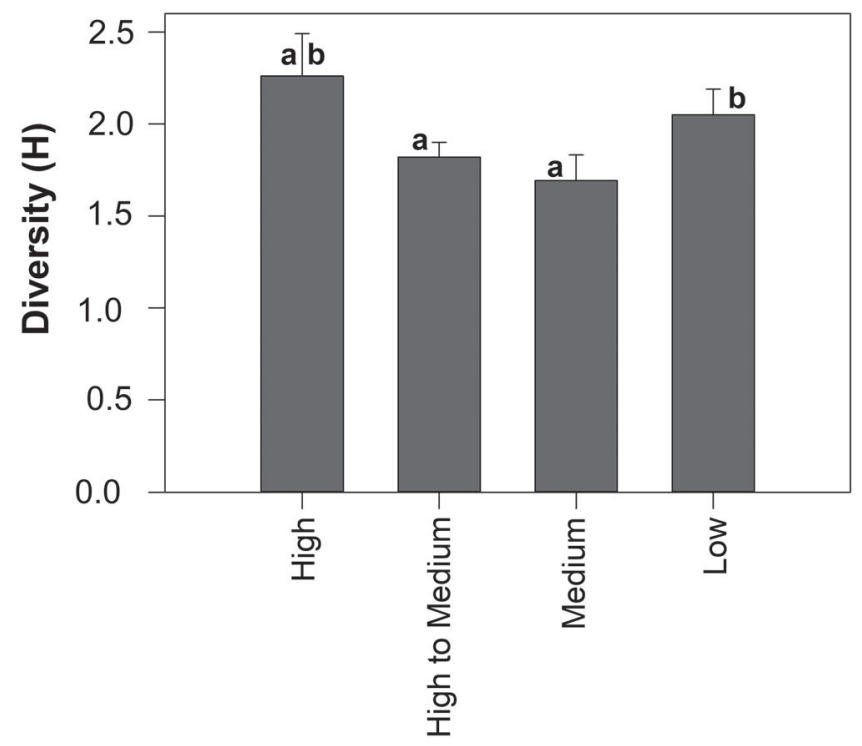

Forest type (by altitude)

Figure 3. Odonata diversity across the elevation zones [high ( $>1800 \mathrm{~m})$, high to medium (1400-1800m), medium $(1000-1400 \mathrm{~m})$ and low $(<1000 \mathrm{~m})]$. Different letters denote significant differences $(p<0.05)$ among elevations. Error bars are based on standard deviations.

Phaon iridipennis, Agriocnemis exilis and Pseudagrion glaucum. Platycypha inyangae, Chlorocypha consueta and Pseudagrion salisburyense were associated with small mountain streams with quiet pools and streams with invasive alien trees. Pseudagrion hamoni, Pseudagrion hageni, Platycypha caligata, Allocnemis marshalli, Lestes virgatus, and Lestes plagiatus were associated with sluggish rivers with quiet pools and swift rivers. Elattoneura glauca was associated with 


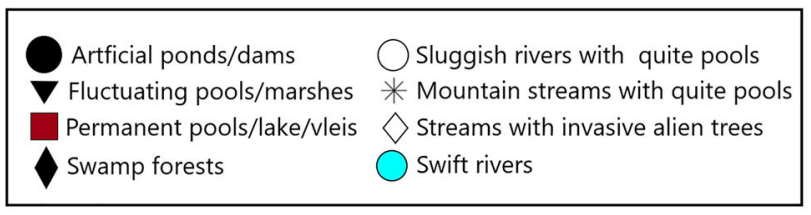

(a) Anisoptera

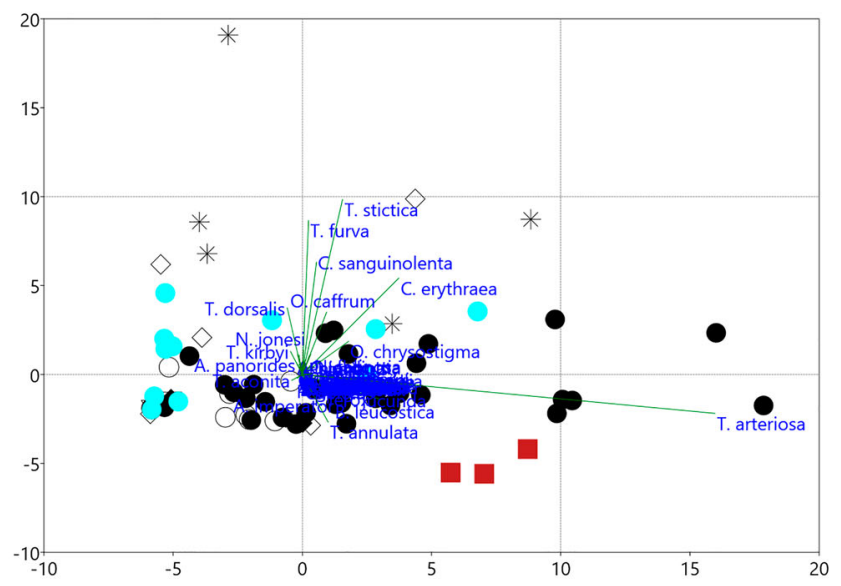

(b) Zygoptera

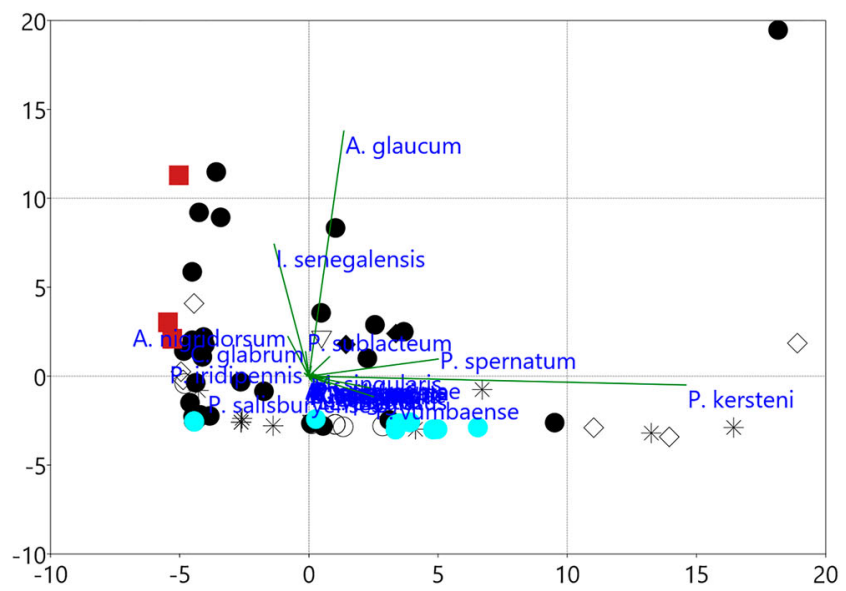

Figure 4. Biplots based on a PCA illustrating the associations between the aquatic biotopes (adapted from Samways et al., 2005) and (a) Anisoptera (first two axes explain $47.3 \%$ of the total variation) and (b) Zygoptera species (first two axes explain $66.8 \%$ of the total variation) recorded from the Afromontane region of Zimbabwe between August 2016 and June 2017.

streams with alien invasive trees. Pseudagrion vumbaense, Pseudagrion kersteni, Pseudagrion spernatum and Africallagma glaucum were found to not have any specific biotope requirements (Figure 4b).

In support of PCA analyses, IndVal analysis revealed that Ischnura senegalensis was associated with streams with invasive alien trees, while Proischnura subfurcata, Africallagma glaucum, Pseudagrion assegaii and Agriocnemis exilis were associated with swamp forests (Table 1). 
Table 1. IndVal analysis of species that associated with specific habitat types. Only significant $(p<0.05)$ habitat associations are presented. The significance of IndVal indices was assessed using 10,000 Monte Carlo permutations.

\begin{tabular}{lllll}
\hline Species & \multicolumn{1}{c}{ Habitat } & Indval & $p$ & Freq \\
\hline Lotic & & & & \\
Ischnura senegalensis & Streams with invasive trees & 0.42 & 0.029 & 4 \\
Proischnura subfurcata & Swamp forests & 0.70 & 0.008 & 4 \\
Africallagma glaucum & Swamp forests & 0.58 & 0.022 & 7 \\
Pseudagrion assegaii & Swamp forests & 0.50 & 0.048 & 1 \\
Agriocnemis exilis & Swamp forests & 0.42 & 0.033 & 2 \\
Lentic & Permanent pools, lakes, & 0.89 & 0.001 & 12 \\
Ischnura senegalensis & $\quad$ vleis or marshes & & & \\
&
\end{tabular}

\section{Anthropogenic threats (objective 3)}

Lotic habitats located within the protected and undisturbed sites had a significantly higher diversity compared to the sites located within protected areas, where vegetation was regularly cleared and modified for tourism. The protected and undisturbed sites had significantly higher diversity compared to sites located in the communal areas, in plantations with extensive mining activities. The endemic species, $P$. inyangae was recorded at a site that fell outside the protected area along the Haroni River. Communal settlements and related activities including fishing using mosquito nets and stream bank cultivation were identified at this site. Another endemic species, Pseudagrion vumbaense, was also recorded outside the protected area in swampy area near Chikware dam. However, it is worth noting that this area had been reforested with exotic pine trees (K. Mafuwe, personal observations, June 2017).

\section{Discussion}

\section{Diversity and distribution (Objective 1)}

The Libellulidae family had the greatest number of species, supporting the notion that this family is generalist, widespread and can easily migrate and adapt to a wide range of habitats (Van Huyssteen \& Samways, 2009). Libellulidae as a group are known to be resilient to changing environmental conditions (Van Huyssteen \& Samways, 2009). Trithemis arteriosa was the most abundant species (Table S2) probably because this species can inhabit a range of habitats, including both open and shaded forests along lotic systems (Damm \& Hadrys, 2012). Regarding Zygoptera species, Pseudagrion kersteni was the most abundant species, in accordance with IUCN reports that suggest that Pseudagrion kersteni is widely distributed across Africa with no documented threats (IUCN, 2019).

Of the four endemic species recorded in the study region (Dijkstra \& Clausnitzer, 2014), only two were found during this study: Platycypha inyangae and Pseudagrion vumbaense. Africallagma cuneistigma and Elattoneura lapidaria were not recorded during sampling, probably due to declining populations. However, an increased sampling effort is needed to test this notion. Because of the rarity of Elattoneura lapidaria, which is known to occur along open rocky streams and patches far from streams (Dijkstra \& Clausnitzer, 2014), more targeted sampling is needed to find this species.

We found odonate generalists and heliophilic species to be ubiquitous (e.g. T. arteriosa and $P$. kersteni) along the biodiversity hotspot. The dominance of generalists may indicate land use 
changes from agriculture that favour generalist species than natural habitats that favour specialized species (Devictor, Julliard, \& Jiguet, 2008). Researchers have documented T. arteriosa to be most abundant in agricultural habitats (e.g. Seidu, Danquah, Nsor, Amaning Kwarteng, \& Lancaster, 2017). We only recorded a single specimen of Z. fuelleborni at the Nyamukwarara river (the widest river in our study). Zygoniodes fuelleborni, as a specialist species that inhabits wide rivers (Dijkstra \& Clausnitzer, 2014), was expected to be present in this Nyamukwarara river. However, the chemicals from illegal mining activities that discharge chemicals into the Nyamukwara river (K. Mafuwe, personal observation, June 2017; Chipangura, 2017) may explain the low abundance of $Z$. fuelleborni recorded in this study.

In protected areas, lotic systems had a significantly higher diversity of odonates compared to lentic habitats (Figure 2). Dams and pools in protected areas of Zimbabwe are used mainly for tourist water supply and recreational activities (e.g. angling and swimming). Therefore, there are more anthropogenic activities around these lentic habitats that possibly alter natural habitats and behaviour of odonates. In contrast, the lentic habitats in the unprotected areas had a significantly higher diversity of odonates compared to the lotic systems. This may be attributed to the increased supply of artificial water bodies built in several communal areas, which may subsequently increase local dragonfly diversity (Deacon, Samways \& Pryke, 2018; Simaika, Samways \& Frenzel, 2016).

Pools, marshes and lakes in unprotected areas had a significantly higher species diversity compared to species found in similar habitats in the protected areas; this may be explained by the higher concentration of lentic water bodies, particularly dams in Zimbabwe found in unprotected areas compared to protected areas. For instance, Van der Mheen (1994) reported only 87 dams out of 9818 to be found in national parks and forests compared to the other land use classifications in Zimbabwe.

Despite having fewer sampling sites of lotic habitats in protected areas compared to unprotected areas, the species diversity of odonatans found at lotic habitats in protected areas were significantly higher compared to similar habitats outside protected areas. This may be due to the impacts on the quality of rivers by the increased supply of artificial water bodies such as dams as they tend to alter aquatic ecology and river hydrology upstream and downstream, thereby reducing the quantity and breeding grounds for a number of aquatic species including Odonata, along the lotic habitats (Helland-Hansen, Holtedahl, \& Lye, 1995). Additionally, the low diversity of odonatans along the rivers in unprotected areas may also be attributed to the high levels of stream bank cultivations that is apparent in many areas in the Eastern Highlands, such as the Pungwe River basin, as well as the effluent from illegal mining activities that occur along rivers such as the Nyamukwarara River and Mutare River (Chipangura, 2017; Nyikadzino, 2016).

Odonata diversity at low elevations was greater than at high to medium elevation zones. These differences in elevation could be explained by the fact that the forests within the high to medium and the mid-elevation zones have fertile soils that are extensively used by subsistence farmers; vegetation is constantly being cleared to accommodate these farmers (Timberlake, 2002). Additionally, Timberlake (1994a, 1994b) documented that poaching, collection of firewood and the gathering of traditional herbal medicines that occurs at mid-elevation forests is major threat to biodiversity in these zones. The Chirinda forests were previously much more widespread, having been cleared for agriculture over the last 100 years (Mujuru \& Kundhlande, 2007). Further, higher species diversity of Odonata observed in the low-elevation zones could be attributed to the extreme temperatures and weather conditions experienced in low-elevation zones, that include lower rainfalls and higher temperatures often exceeding $35^{\circ} \mathrm{C}$ in summer (Childes \& Mundy, 1998). These climatic conditions restrict farming in low elevation zones and they consequently have experienced fewer human disturbances in the past; this has helped to maintain the thick forests within these low-elevation valleys. However, there are still patches of unprotected forest 
in these areas that could be lost to communal settlements. Human expansion may soon have an impact on the biodiversity within the valleys (Gandiwa, Matsvayi, Ngwenya, \& Gandiwa, 2011).

\section{Habitat associations (Objective 2)}

Anisoptera species were widespread across the region and occurred within most biotopes. This could be explained by the fact Anisoptera, particularly the Libellulidae family and Aeshnidae, contains a great number of species, e.g. Pantala flavescens, that are widespread and generalist species known to occur across a wide spectrum of habitats and microhabitats (Haritonov \& Popova, 2011; May 2013).

Our data revealed that most Zygoptera species were associated with artificial dams and ponds. Damselflies are smaller species that do not migrate for long distances and therefore prefer perennial habitats that have a long-term supply of water and sites for perching (Rouquette \& Thompson, 2007). Artificial ponds and dams act as reservoirs for rainwater, especially during dry periods (de Santos Loureiro, 2012; Kosterin, 2010). As such, they provide microhabitats, perch sites and artificial breeding sites that can support many species; this is in agreement with other researchers (Oertli et al., 2002). Moreover, artificial ponds and dams were the most abundant freshwater habitats identified and surveyed during this study (Table S1).

Ischnura senegalensis was associated with streams with invasive alien trees. Exotic trees, especially wattle, pine and eucalyptus trees, are common in rivers, due the exotic timber plantations found in the Eastern Highlands of Zimbabwe (Tembani, Madhibha, Marunda, \& Gapare, 2014). These habitats are characterized by extensive human disturbance from logging by timber companies and illegal settlers that have invaded parts of the commercial forests (Jimu \& Nyakudya, 2018; Zisadza-Gandiwa et al., 2014). These conditions tend to make these rivers depauperate in dragonfly species, and even threatening some with extinction (Samways, 2008; Samways \& Grant, 2006). However, I. senegalensis is very widely distributed around the globe, and it is known to be highly tolerant to disturbed and polluted conditions and may be present in trampled waterholes (Lambertz \& Schmied, 2011; Samways, 2008), which could explain its association with these habitats.

Proischnura subfurcata, Africallagma glaucum, Pseudagrion assegaii and Agriocnemis exilis were associated with swamp forests in accordance with the habitats described by Dijkstra \& Clausnitzer (2014), who reported all species to occur in grassy, marshy and swampy habitats that are often stagnant and temporary. Proischnura subfurcata was reported to particularly occur in marshes found in mountainous areas. Samways (2008) did, however, report two specimens of $P$. subfurcata to occur in grassy and reedy reaches of streams found in non-mountainous and low-lying areas of South Africa, though the need for confirmation was noted as it was uncertain that these two records were indeed correct identification of the species.

\section{IUCN evaluations and threats to Odonata}

Three species that are considered vulnerable according to IUCN (2019) were recorded in the Eastern Highlands of Zimbabwe during this research (Table S2). We did not find the following endemic species: Africallagma cuneistigma and Elattoneura lapidaria. Further sampling (including active searches for naiads) is needed to determine the distribution and range of these species. This information will be essential to updating the IUCN Red List on the status of these species; this is particularly true considering that the Eastern Highlands will continue to experience huge land use changes related to a continuously increasing population.

Commercial tree plantations, mining activities, vegetation clearing and landscape modification for tourism and communal settlements were identified as potential threats to odonates in the 
Eastern Highlands Biodiversity Hotspot of Zimbabwe (K. Mafuwe, personal observation, June 2017). The impacts appear to be greatest in areas whose trees have been harvested and cleared. These anthropogenic factors can potentially threaten the existence of freshwater species including the endemic species, $P$. inyangae, that we recorded at a site that fell outside the protected area along the Haroni River. Seidu et al. (2017) documented that disturbance causes reductions in stenotopic and perching odonate species assemblages due to the loss of the complex structure of the forest canopy. Our findings and those of other researchers (e.g. Biervliet, Wiśniewski, Daniels, \& Vonesh, 2009) suggest that deforestation does not only render habitats unsuitable for the colonization and reproduction for forest specialist species, but also threatens forest freshwater biota.

\section{Summary and additional considerations for conservation}

Our results illustrated how the diversity and distribution of Odonata species differs among habitats with varying land use activities. The findings have direct significance for our understanding of the environmental pressures on freshwater diversity, and broader implications for a region that is considered the source of endemism in Southern Africa. We recommend the inclusion of several diversity studies in different landscape characteristics to unravel some of the other land use changes that can affect freshwater animals.

\section{Ethical declaration}

Relevant permits were obtained from the Park and Wildlife Management Authority of Parks of Zimbabwe [Permit number: 23 (1) (C) (II) 18/2017 and 23 (I) (C) (II) 62/2017]. Fauna and flora were not harmed in any way during the study.

\section{Acknowledgements}

This research was funded by the Critical Ecosystem Partnership Fund (CEPF), a joint initiative of l'Agence Française de Développement, Conservation International, the European Union, the Global Environment Facility, the Government of Japan, the MacArthur Foundation and the World Bank.

\section{Supplemental data}

Supplemental data for this article can be accessed https://doi.org/10.1080/13887890.2020.1768156.

\section{ORCID}

Kudzai Mafuwe (iD http://orcid.org/0000-0002-2018-9758

Sydney Moyo (D) http://orcid.org/0000-0002-9286-6578

\section{References}

Allan, J. D., \& Castillo, M. M. (2007). Stream Ecology: Structure and Function of Running Waters (2nd ed.). Dordrecht, the Netherlands: Springer.

Bhusnar, A. R., \& Sathe, T. V. (2017). Biology of a dragonfly Crocothemis Servilia Drury (Odonata: Libellulidae), a predator of paddy pests in Kolhapur. Journal of Pharmacy and Biological Sciences, 12(3), 18-20. doi:10.9790/3008-1203011820.

Biervliet, O. V., Wiśniewski, K., Daniels, J., \& Vonesh, J. R. (2009). Effects of tea plantations on stream invertebrates in a global biodiversity hotspot in Africa. Biotropica, 41(4), 469-475. doi:10.1111/j.1744-7429.2009.00504.x. 
Bouchelouche, D., Kherbouche-Abrous, O., Mebarki, M., Arab, A., \& Samraoui, B. (2015). The Odonata of Wadi Isser (Kabylia, Algeria): status and environmental determinants of their distribution. Revue d'Ecologie (Terre et Vie), 70(3), 48-260. http://documents.irevues.inist.fr/bitstream/handle/2042/56759/RevuedEcologie_2015_70_3_248. pdf? sequence $=1$

Branch, W. R., Bayliss, J., \& Tolley, K. A. (2014). Pygmy chameleons of the Rhampholeon platyceps complex (Squamata: Chamaeleonidae): Description of four new species from isolated 'sky islands' of northern Mozambique. Zootaxa, 3814(1), 1-36. doi:10.11646/zootaxa.3814.1.1

Childes, S. L., \& Mundy, P. J. (1998). Important Bird Areas of Zimbabwe. In K. N. Barnes (Ed.), The important bird areas of southern Africa (pp. 355-384). Johannesburg, South Africa: BirdLife International.

Chipangura, N. (2017). Archaeological Technologies of Gold Mining and Processing and their Relationship to Contemporary Chikorokoza: The Case of Mutanda Site, Mutare, Zimbabwe. In A. Nemachena \& T. V. Warikandwa (Eds.), Mining Africa: Law, environment, society and politics in historical and multidisciplinary perspectives (p. 103). Bemenda, Cameroon: Langaa Research and Publishing Common Initiative Group. doi:10.2307/j.ctvh9vz92.6

Clausnitzer, V., Dijkstra, K.-D. B., Koch, R., Boudot, J. P., Darwall, W. R. T., Kipping, J., \& Suhling, F. (2012). Focus on African freshwaters: Hotspots of dragonfly diversity and conservation concern. Frontiers in Ecology and the Environment, 10, 129-134. doi:10.1890/110247

Clausnitzer, V., Kalkman, V. J., Ram, M., Collen, B., Baillie, J. E., Bedjanič, M., \& Karube, H. (2009). Odonata enter the biodiversity crisis debate: the first global assessment of an insect group. Biological Conservation, 142(8), 18641869. doi:10.1016/j.biocon.2009.03.028

Clausnitzer, V., Simaika, J. P., Samways, M. J., \& Daniel, B. A. (2017). Dragonflies as flagships for sustainable use of water resources in environmental education. Applied Environmental Education \& Communication, 16(3), 196-209. doi:10.1080/1533015X.2017.1333050

Dalu, T., Sachikonye, M. T., Alexander, M. E., Dube, T., Froneman, W. P., Manungo, K. I., \& Wasserman, R. J. (2016). Ecological assessment of two species of Potamonautid freshwater crabs from the eastern highlands of Zimbabwe, with implications for their conservation. PloS one, 11(1), e0145923. doi:10.1371/journal.pone.0145923

Damm, S., Dijkstra, K.-D. B., \& Hadrys, H. (2010). Red drifters and dark residents: the phylogeny and ecology of a Plio-Pleistocene dragonfly radiation reflects Africa's changing environment (Odonata, Libellulidae, Trithemis). Molecular Phylogenetics and Evolution, 54(3), 870-882. doi:10.1016/j.ympev.2009.12.006

Damm, S., \& Hadrys, H. (2012). A dragonfly in the desert: genetic pathways of the widespread Trithemis arteriosa (Odonata: Libellulidae) suggest male-biased dispersal. Organisms Diversity \& Evolution, 12(3), $267-279$. doi:10.1007/s13127-012-0079-1

Darwall, W. R. T., Smith, K. G., Tweddle, D., \& Skelton, P. (Eds.) (2009). The Status and Distribution of Freshwater Biodiversity in Southern Africa. Gland,Switzerland: IUCN and Grahamstown, South Africa: SAIAB, viii + 120 pp. https://portals.iucn.org/library/sites/library/files/documents/RL-68-003.pdf

Deacon, C., Samways, M. J., \& Pryke, J. S. (2018). Artificial reservoirs complement natural ponds to improve pondscape resilience in conservation corridors in a biodiversity hotspot. PloS one, 13(9), e0204148. doi:10.1371/journal.pone.0204148

de Oliveira-Junior, J. M. B., Junior, P. D. M., Dias-Silva, K., Leitão, R. P., Leal, C. G., Pompeu, P. S., Gardner, Juen, L. (2017). Effects of human disturbance and riparian conditions on Odonata (Insecta) assemblages in eastern Amazon basin streams. Limnologica-Ecology and Management of Inland Waters, 66, 31-39. doi:10.1016/j.limno.2017.04.007

de Santos Loureiro, N. (2012). New data on the distribution of Orthetrum trinacria in the Algarve, southern Portugal (Odonata: Libellulidae). Libellula, 31, 77-87.

Devictor, V., Julliard, R., \& Jiguet, F. (2008). Distribution of specialist and generalist species along spatial gradients of habitat disturbance and fragmentation. Oikos, 117(4), 507-514. doi:10.1111/j.0030-1299.2008.16215.x

Dijkstra, K.-D. B., \& Clausnitzer, V. (2014). The dragonflies and damselflies of eastern Africa: Handbook for all Odonata from Sudan to Zimbabwe. Tervuren, Belgium: Belgian Royal Museum for Central Africa.

Dijkstra, K.-D. B., Clausnitzer, V., Mézière, N., Kipping, J., \& Schütte, K. (2011). The status and distribution of dragonflies and damselflies (Odonata) in central Africa. In: Brooks, E. G. E., Allen, D., \& Darwall, W. R. T. (Compilers). The status and distribution of freshwater biodiversity in Central Africa. Gland, Switzerland and Cambridge, UK: IUCN, 62-76.

Dijkstra, K.-D. B., \& Kipping, J. (2013). Odonata Database of Africa. Biofresh. Retrieved 29 November 2017 from http://data.freshwaterbiodiversity.eu doi:10.13148/bfcf21

Dube, T., Makaka, C., \& Sibanda, Z. (2010). An assessment of the effect of industrial and sewage effluent on aquatic invertebrates: A case study of a southern urban stream, Zimbabwe. Journal of Sustainable Development, 3(2), 210. doi:10.5539/jsd.v3n2p210

Dufrêne, M., \& Legendre. P. (1997). Species assemblages and indicator species: The need for a flexible asymmetrical approach. Ecological Monographs, 67, 345-366. doi:10.2307/2963459

Dumont, H. J., \& Verschuren, D. (2005). Odonata from the Ennedi and Ounianga regions of northern Chad, with a note of the status of Orthetrum kollmannspergeri Buchholz, and a checklist of species currently known from the Republic of Chad. Odonatologica, 34(3), 291-297. URL: http://hdl.handle.net/1854/LU-342230

Faithpraise, F. O., Idung, J., Usibe, B., Chatwin, C. R., Young, R., \& Birch, P. (2014). Natural control of the mosquito population via Odonata and Toxorhynchites. International Journal of Innovative Research in Science, Engineering and Technology, 3(5), 12898-12911. http://sro.sussex.ac.uk/id/eprint/49045

Gandiwa, E., \& Gandiwa, P. (2012). Biodiversity conservation versus artisanal gold mining: a case study of Chimanimani National Park, Zimbabwe. Journal of Sustainable Development in Africa, 14(6), 29-37. 
Gandiwa, P., Matsvayi, M., Ngwenya, M. M., \& Gandiwa, E. (2011). Assessment of livestock and human settlement encroachment into northern Gonarezhou National Park, Zimbabwe. Journal of Sustainable Development in Africa, 13(5), 19-33.

Harisha, M., \& Hosetti, B. (2017). Conservation status, threats and diversity of Odonates in Kuvempu University Campus, Mid-Western Ghats, Shivamogga district, Karnataka, India. Journal Entomology and Zoology Studies, 5(52), 389-393.

Haritonov, A., \& Popova, O. (2011). Spatial displacement of Odonata in south-west Siberia. International Journal of Odonatology, 14(1), 1-10. doi:10.1080/13887890.2011.568188

Hart, L. A., Bowker, M. B., Tarboton, W., \& Downs, C. T. (2014). Species composition, distribution and habitat types of Odonata in the iSimangaliso Wetland Park, KwaZulu-Natal, South Africa and the associated conservation implications. PLoS One, 9(3), p.e92588. doi:10.1371/journal.pone.0092588

Helland-Hansen, E., Holtedahl, T., \& Lye, K. A. (1995). Environmental effects. Trondheim, Norway: Norwegian Institute of Technology, Division of Hydraulic Engineering.

Hemalatha, R. (2017). Bioindicators: A review. International Journal of Animal Biotechnology and Applications, 3(1), 22-38. doi:10.37628/ijaba.v3i1.163

IUCN (2019). The IUCN Red List of Threatened Species. Version 2019-2. Retrieved on 20 November 2019 from http://www.iucnredlist.org

Jimu, L., \& Nyakudya, I. W. (2018). Fires in exotic forest plantations of Zimbabwe: Causes and management strategies. World Development Perspectives, 9, 56-58. doi:10.1016/j.wdp.2018.04.006

Jonnalagadda, S. B., \& Mhere, G. (2001). Water quality of the Odzi River in the eastern highlands of Zimbabwe. Water Research, 35(10), 2371-2376. doi:10.1016/s0043-1354(00)00533-9

Kemabonta, K. A., Adu, B. W., \& Ohadiwe, A. C. (2017). Impact of human disturbance on the abundance, diversity and distribution of Odonata in the University of Lagos, Akoka, Lagos, Nigeria. Applied Tropical Agriculture, 21(3), $143-150$.

Khan, M. K. (2015). Dragonflies and damselflies (Insecta: Odonata) of the Northeastern region of Bangladesh with five new additions to the Odonata fauna of Bangladesh. Journal of Threatened Taxa, 7(11), 7795-7804. doi:10.11609/JoTT.o4314.7795-804

Kipping, J., Dijkstra, K.-D. B., Clausnitzer, V., Suhling, F., \& Schütte, K. (2009). Odonata database of Africa (ODA). Agrion, 13, 20-23.

Kosterin, O. E. (2010). A glance at the Odonata of the Cambodian coastal mountainous regions: end of dry season in 2010. International Dragonfly Fund, 29, 1-75.

Lambertz, M., \& Schmied, H. (2011). Records of the exotic damselfly Ischnura senegalensis (Rambur, 1842) from Bonn (Germany). Bonn Zoological Bulletin, 60(2), 211-213.

Lamsal, P., Pant, K., Kumar, L., \& Atreya, K. (2015). Sustainable livelihoods through conservation of wetland resources: a case of economic benefits from Ghodaghodi Lake, western Nepal. Ecology and Society, 20(1). 10. doi:10.5751/ES-07172-200110

Lopes-Lima, M., Sousa, R., Geist, J., Aldridge, D. C., Araujo, R., Bergengren, J., \& Douda, K. (2017). Conservation status of freshwater mussels in Europe: state of the art and future challenges. Biological Reviews, 92(1), 572-607. doi:10.1111/brv. 12244

Makaure, J., Makaka, C., Sithole, M., Moyo, D. Z., Baudi, I., Mufandaedza, E., \& Bwangamoi, O. (2015). Assessment of upper thermal tolerances of naiads of two odonate families: Coenagrionidae and Libellulidae in Lake Kariba, Zimbabwe. Applied Zoology, 80, 31201-31206.

May, M. L. (2013). A critical overview of progress in studies of migration of dragonflies (Odonata: Anisoptera), with emphasis on North America. Journal of Insect Conservation, 17(1), 1-15. doi:10.1007/s10841-012-9540-x

Mujuru, L., \& Kundhlande, A. (2007). Small-scale vegetation structure and composition of Chirinda Forest, southeast Zimbabwe. African Journal of Ecology, 45(4), 624-632. doi:10.1111/j.1365-2028.2007.00786.x

Mukheibir, P. (2017). Possible climate change impacts on large hydroelectricity schemes in Southern Africa. Journal of Energy in Southern Africa, 18(1), 4-9. doi:10.17159/2413

Ndunguru, E., Dondeyne, S., \& Mulaboa, J. (2006). Illegal gold mining in the Chimanimani National Reserve: environmental and socio-economic assessment. Retrieved from http://www.eisourcebook.org/cms/Feb202013/Illegal20 gold20mining20in20the20Chimanimani20National20Reserve.pdf

Nyikadzino, B. (2016). Assessing the effectiveness of environmental management structures and participation process in the upper Pungwe River Basin, Zimbabwe (Doctoral dissertation). Retrieved from http://uir.unisa.ac.za/handle/10500/21212 3051/2007/v18i1a3340

Oertli, B., Joye, D. A., Castella, E., Juge, R., Cambin, D., \& Lachavanne, J. B. (2002). Does size matter? The relationship between pond area and biodiversity. Biological Conservation, 104(1), 59-70. doi:10.1016/S0006-3207(01)00154-9

Podani, J., \& Csányi. B. (2010). Detecting indicator species: Some extensions of the IndVal measure. Ecological Indicators, 10, 1119-1124. doi:10.1016/j.ecolind.2010.03.010

Pinhey, E. (1961). A survey of the dragonflies (Order Odonata) of Eastern Africa. London, UK: British Museum.

Pinhey, E. C. (1984). A check-list of the Odonata of Zimbabwe and Zambia. Bulawayo, Zimbabwe: National Museums and Monuments of Zimbabwe.

Rouquette, J. R., \& Thompson, D. J. (2007). Patterns of movement and dispersal in an endangered damselfly and the consequences for its management. Journal of Applied Ecology, 44(3), 692-701. doi:10.1111/j.1365-2664.2007. 01284.X

Samways, M. J. (2002). Red-listed Odonata of Africa. Odonatologica, 31(2), 151-170.

Samways, M. J. (2008). Dragonflies and damselflies of South Africa. Sofia, Bulgaria: Pensoft Publishers. 
Samways, M. J., \& Grant, P. B. C. (2006). Regional response of Odonata to river systems impacted by and cleared of invasive alien trees. Odonatologica, 35(3), 297-303.

Seidu, I., Danquah, E., Nsor, C. A, Amaning Kwarteng, D., \& Lancaster, L. T. (2017). Odonata community structure and patterns of land use in the Atewa Range Forest Reserve, Eastern Region (Ghana). International Journal of Odonatology, 20, 173-189. doi:10.1080/13887890.2017.1369179

Simaika, J. P., Samways, M. J., \& Frenzel, P. P. (2016). Artificial ponds increase local dragonfly diversity in a global biodiversity hotspot. Biodiversity and conservation, 25(10), 1921-1935. doi:10.1007/s10531-016-1168-9

Sterling, E. J., Betley, E., Sigouin, A., Gomez, A., Toomey, A., Cullman, G., \& Filardi, C. (2017). Assessing the evidence for stakeholder engagement in biodiversity conservation. Biological Conservation, 209, 159-171. doi:10.1016/j.biocon.2017.02.008

Suhling, F., Samways, M. J., Simaika, J. P., \& Kipping, J. (2009). The status and distribution of dragonflies (Odonata). In: W. R. T. Darwall, K. G. Smith, D. Tweddle \& P. Skelton (Eds.), The Status and Distribution of Freshwater Biodiversity in Southern Africa (pp. 48-65). Gland, Switzerland: IUCN and Grahamstown, South Africa: SAIAB.

Tembani, M., Madhibha, T., Marunda, C. T., \& Gapare, W. J. (2014). Sustaining and improving forest genetic resources for Zimbabwe: lessons from 100 years. International Forestry Review, 16(6), 615-632. doi:10.1505/146554814814095339

Terink, W., Droogers, P., \& en Aa's, W. H. (2014). Hydrological analysis and modelling of the Pungwe River Basin, Mozambique. Report Future Water, 126, 1-56.

Timberlake, J. (1994a). Changes in the extent of moist forest patches in the eastern highlands: case studies based on aerial photographs. Zimbabwe Forestry Commission Research Paper, 7, 1-15.

Timberlake, J. (1994b). Physical features of the Chirinda forest. In Chirinda Forest - a visitor's guide. Harare, Zimbabwe: Forestry Commission.

Timberlake, J. (2002). The Biodiversity and Ecology of Chirinda Forest. Bulawayo book club BFA Seminar Series 17. URL: http://www.biodiversityfoundation.org/documents/s17.pdf.

Van der Mheen, H. W. (1994). Practical aspects of stocking small water bodies: an example from Zimbabwe. CIFA Technical Paper, 28, 1-40.

Van Huyssteen, P., \& Samways, M. J. (2009). Overwintering dragonflies in an African savanna (Anisoptera: Gomphidae, Libellulidae). Odonatologica, 38(2), 167-172.

Zisadza-Gandiwa, P., Gandiwa, E., Matokwe, T. B., Gwazani, R., Mashapa, C., Muboko, N., \& Mudangwe, S. (2014). Preliminary assessment of vegetation fires and their impact in Nyanga National Park, Zimbabwe. Greener Journal of Biological Sciences, 4(1), 10.

Zuo, D., Xu, Z., Yao, W., Jin, S., Xiao, P., \& Ran, D. (2016). Assessing the effects of changes in land use and climate on runoff and sediment yields from a watershed in the Loess Plateau of China. Science of the Total Environment, 544, 238-250. doi:10.1016/j.scitotenv.2015.11.060 